\title{
PRODUÇÃO DE BIOMASSA DE Calendula officinalis L. ADUBADA COM FÓSFORO E CAMA-DE-FRANGO
}

\author{
Biomass yield of Calendula officinalis L. fertilized with phosporus and chicken manure
}

\author{
Valdenise Carbonari Barboza ${ }^{1}$, Maria do Carmo Vieira ${ }^{2}$, Néstor Antonio Heredia Zárate ${ }^{3}$, \\ Simone Priscila Botega ${ }^{4}$, Neriane de Souza Padilha ${ }^{5}$, Caroline Leite Paes $^{6}$
}

\begin{abstract}
RESUMO
Objetivou-se, neste trabalho, avaliar a influência do fósforo e da cama-de-frango semidecomposta na produção de capítulos florais da Calendula officinalis L. Os fatores em estudo foram cinco doses de fósforo $\left(4,3 ; 25,8 ; 43,0 ; 60,2 ; 81,7 \mathrm{~kg}_{\text {ha }}{ }^{-1} \mathrm{de}_{\mathrm{P}} \mathrm{P}_{5}\right)$, na forma de superfosfato triplo e cinco doses de cama-de-frango semidecomposta $\left(1.000 ; 6.000 ; 10.000 ; 14.000 \mathrm{e} 19.000 \mathrm{~kg} \mathrm{ha}^{-1}\right)$. Para combinar o fósforo e a cama-de-frango, usou-se a matriz experimental Plan Puebla III resultando em nove tratamentos (25,8 e 6.000; 60,2 e 6.000; 25,8 e 14.000; 60,2 e 14.000; 43,0 e 10.000; 4,3 e 6.000; 81,7 e 14.000; 25,8 e 1.000; 60,2 e 19.000 kg ha $^{-1}$ de P e cama-de-frango, respectivamente) no delineamento de blocos casualizados, com quatro repetições. A altura média final das plantas, aos 120 dias, ficou em torno de $60,0 \mathrm{~cm}$, independente dos tratamentos. A produção máxima de capítulos florais da calêndula foi de $9.755,16$ mil ha $^{-1}, \mathrm{obtida} \mathrm{com}^{-}$ o uso de 49,15 kg ha ${ }^{-1}$ de $\mathrm{P}_{2} \mathrm{O}_{5}$ associada a $13.401,10 \mathrm{~kg} \mathrm{ha}^{-1}$ de cama-de-frango A maior produção $\left(11.058,89 \mathrm{~kg} \mathrm{ha}^{-1}\right)$ de massa fresca de capítulos florais de calêndula foi obtida com 49,98 kg ha-1 de $\mathrm{P}_{2} \mathrm{O}_{5}$ e 13.266,59 $\mathrm{kg} \mathrm{ha}^{-1}$ de cama-de-frango. As produções máximas de massas secas de capítulos florais $\left(2.227,61 \mathrm{~kg} \mathrm{ha}^{-1}\right)$ foram obtidas com $39,62 \mathrm{~kg} \mathrm{ha}^{-1}$ de $\mathrm{P}_{2} \mathrm{O}_{5}$ e $8.109,75 \mathrm{~kg} \mathrm{ha}^{-1}$ de cama-de-frango. Concluiu-se que para se obter maior produção de massa seca de capítulos florais, componente de maior importância comercial, a calêndula deve ser cultivada utilizando adubação com $\mathrm{HH} 40 \mathrm{~kg} \mathrm{ha}^{-1} \mathrm{de}_{2} \mathrm{O}_{5}$ e H" $8.000 \mathrm{~kg} \mathrm{ha}^{-1}$ de cama-de-frango.
\end{abstract}

Termos para indexação: Calêndula, nutrição mineral, resíduo orgânico.

\section{ABSTRACT}

The aim of this work was to evaluate the influence of phosphorus and semi-decomposed chicken manure on capitula yield of Calendula officinalis $\mathrm{L}$. The studied factors were five doses of phosphorus $\left(4.3,25.8,43.0,60.2\right.$, and $\left.81.7 \mathrm{~kg} \mathrm{ha}^{-1} \mathrm{P}_{2} \mathrm{O}_{5}\right)$ in the triple super phosphate form and five doses of semi-decomposed chicken manure $\left(1000,6000,10000,14000\right.$, and $\left.19000 \mathrm{~kg} \mathrm{ha}^{-1}\right)$. The Plan Puebla experimental matrix was used to combine phosphors and chicken manure, which resulted in nine treatments, viz. $25.8+6000,60.2+$ $6000,25.8+14000,60.2+14000,43.0+10000,4.3+6000,81.7+14000,25.8+1000$, and $60.2+19000$ (first figure representing kg $\mathrm{ha}^{-1} \mathrm{P}$; second figure, $\mathrm{kg} \mathrm{ha}^{-1}$ chicken manure) in randomized block design with four replications. Final average heights of plants at 120 days were about $60.0 \mathrm{~cm}$, independently of the treatments. Maximum yield of pot marigold capitula was $9755.16 \times 10^{3} \mathrm{ha}^{-1}$, which was obtained with the use of $49.15 \mathrm{~kg} \mathrm{ha}^{-1} \mathrm{P}_{2} \mathrm{O}_{5}$ associated to $13401.10 \mathrm{~kg} \mathrm{ha}^{-1}$ chicken manure The highest yield $\left(11058.89 \mathrm{~kg} \mathrm{ha}^{-1}\right)$ of fresh biomass of pot marigold capitula was obtained with $49.98 \mathrm{~kg} \mathrm{ha}^{-1} \mathrm{P}_{\mathrm{O}_{5}}$ and $13266.59 \mathrm{~kg} \mathrm{ha}^{-1}$ chicken manure. Maximum yields of dried mass of capitula (2227.61 kg ha-1) were obtained with $39.62 \mathrm{~kg} \mathrm{ha}^{-1} \mathrm{P}_{2} \mathrm{O}_{5}$ and $8109.75 \mathrm{~kg} \mathrm{ha}^{-1}$ chicken manure. It was concluded that to obtain the greatest dried mass yield of capitula, which constituent the most important commercial product of pot marigold, the plant must be cultivated using fertilization with $\mathrm{H}^{\prime \prime} 40 \mathrm{~kg} \mathrm{ha}^{-1} \mathrm{P}_{2} \mathrm{O}_{5}$ and $\mathrm{H}^{\prime} 8000 \mathrm{~kg} \mathrm{ha}^{-1}$ chicken manure.

Index terms: Pot marigold, mineral fertilization, organic residue.

(Recebido em 2 de agosto de 2007 e aprovado em 28 de agosto de 2008)

\section{INTRODUÇÃO}

A calêndula (Calendula officinalis L.- Asteraceae), também conhecida como malmequer, maravilha, malmequer-dos-jardins e margarida-dourada é originária da Europa. As partes usadas como terapêuticas podem ser as folhas ou as inflorescências (capítulos florais), que apresentam coloração amarela, alaranjada, esverdeada ou amarelas com o centro avermelhado. Tem ação cicatrizante, antiinflamatória, laxativa, expectorante e antiespasmódica;

\footnotetext{
'Engenheira Agrônoma, Doutoranda em Agronomia - Universidade Federal da Grande Dourados/UFGD - Cx. P. 533 - $79804-970$ - Dourados, MS valcarbonari@hotmail.com

²Engenheira Agrônoma, Doutora, Professora Titular da Faculdade de Ciências Agrárias - Universidade Federal da Grande Dourados/UFGD - Cx. P. 533 79804-970 - Dourados, MS - vieiracm@terra.com.br - Bolsista de Produtividade em Pesquisa do CNPq

${ }^{3}$ Engenheiro Agrônomo, Doutor, Professor Associado I da Faculdade de Ciências Agrárias - Universidade Federal da Grande Dourados/UFGD - Cx. P. 533 79804-970 - Dourados,MS - nahz@terra.com.br - Bolsista de Produtividade em Pesquisa do CNPq

${ }^{4}$ Graduanda em Agronomia - Universidade Federal da Grande Dourados/UFGD - Cx. P. 533 - 79804-970 - Dourados,MS - sibottega@hotmail.com Bolsista de Iniciação Científica do CNPq

${ }^{5}$ Graduanda em Agronomia - Universidade Federal da Grande Dourados/UFGD - Cx. P. 533 - 79804-970 - Dourados-MS - nerianepadilha@ibest.com.br Bolsista de Iniciação Científica do CNPq

${ }^{6}$ Graduanda em Agronomia - Universidade Federal da Grande Dourados/UFGD - Cx. P. 533 - 79804-970 - Dourados,MS - carolleitepaes@bol.com.br Bolsista de Iniciação Científica do CNPq.
} 
além disso, auxilia no fortalecimento dos vasos capilares (DELLA LOGGIA et al., 1994; VENIKAR \& JANDGE, 1993).

Vários trabalhos com a calêndula têm correlacionado sua atividade biológica com a estrutura química, ou seja, as saponinas triterpenoídicas têm atividade antitumoral; os triterpenóides são antiinflamatórios tópicos; os flavonóides são anti-inflamatórios e o éster triterpenodiol é antiedêmico (BEZÁKOVA et al., 1996; DELLA LOGGIA et al., 1994; ZITTERL-EGLSEE et al., 1997). Como fitocosmético é indicada no tratamento de acne, eczemas, abcessos e impetigo, além da prevenção de assaduras de crianças e como protetor contra os raios UVA e UVB. A tintura de calêndula é usada para curar trauma causado por ferimentos da cavidade bucal e no tratamento de hemorragia nas gengivas. Na literatura há citações sobre o emprego da calêndula como reguladora do ciclo menstrual e para o tratamento de verrugas e do câncer de pele (BERTONI et al., 1998; FONT QUER, 1993; SIGEDAR et al., 1991; TESKE \& TRENTINE, 1995).

A calêndula é uma planta anual que se adapta bem aos solos férteis, úmidos e permeáveis, bem drenados, ricos em matéria orgânica, profundos e permeáveis (FUENTES et al., 1986). Segundo Martins et al. (1994), uma adubação equilibrada é fundamental para a obtenção de plantas medicinais mais produtivas, resistentes a pragas e doenças e com maiores teores de fármacos.

Quanto às exigências nutricionais da calêndula, Mattos (1996) afirmou que a adubação nitrogenada é importante para incrementar o desenvolvimento da planta, sendo a sua deficiência caracterizada por redução no crescimento e no tamanho das folhas, diminuindo, portanto, a produção de massas frescas e secas. Moreira et al. (2005) observaram que a adição ao solo de nitrogênio e de fósforo, na forma de uréia e de superfosfato triplo, possibilitou a obtenção das plantas mais altas. Os rendimentos de massa seca da parte aérea e dos capítulos florais ocorreram, no geral, sob dose de $292 \mathrm{mg}$ vaso $^{-1} \mathrm{de}$ $\mathrm{P}_{2} \mathrm{O}_{5}$, na presença das doses mais elevadas de $\mathrm{N}$. Vieira et al. (1999) observaram que a altura média final das plantas de calêndula variou de 29,9 a $39,9 \mathrm{~cm}$, quando cultivadas, respectivamente, com $0 \mathrm{t} \mathrm{ha}^{-1}$ de cama-de-frango $+50 \mathrm{~kg}$ ha $^{-1}$ de $\mathrm{P}_{2} \mathrm{O}_{5}$ na forma de superfosfato simples e $7 \mathrm{t} \mathrm{ha}^{-1} \mathrm{de}$ cama-de-frango $+100 \mathrm{~kg}^{-1} \mathrm{de}_{2} \mathrm{P}_{5}$

Objetivou-se, neste trabalho, avaliar a influência do fósforo e da cama-de-frango semidecomposta na produção de capítulos florais da Calendula officinalis $\mathrm{L}$.

\section{MATERIALE MÉTODOS}

O trabalho foi desenvolvido no Horto de Plantas Medicinais - HPM, da Universidade Federal de Mato
Grosso do Sul, em Dourados-MS, no período de maio a setembro de 2005 em Latossolo Vermelho distroférrico. Os fatores em estudo foram o fósforo $(4,3 ; 25,8 ; 43,0 ; 60,2$; $81,7 \mathrm{~kg} \mathrm{ha}^{-1}$ ), na forma de superfosfato triplo e a cama-defrango semidecomposta $(1.000,6.000,10.000,14.000$ e 19.000 $\left.\mathrm{kg} \mathrm{ha}^{-1}\right)$. Para combinar as doses do fósforo e da cama-defrango usou-se a matriz experimental Plan Puebla III resultando em nove tratamentos ( 25,8 e $6.000 ; 60,2$ e 6.000; 25,8 e 14.000; 60,2 e 14.000; 43,0 e 10.000; 4,3 e 6.000; 81,7 e $14.000 ; 25,8$ e $1.000 ; 60,2$ e $19.000 \mathrm{~kg} \mathrm{ha}^{-1}$ de fósforo e cama, respectivamente), arranjados no delineamento de blocos casualizados, com quatro repetições.

A propagação da calêndula foi por semeadura indireta, utilizando-se sementes (diásporos), provenientes de plantas matrizes cultivadas no HPM. As mudas foram produzidas em saquinhos de polietileno, utilizando-se como substrato a mistura de terra, substrato comercial para hortaliças e areia na proporção de 3:2:1. O terreno no local definitivo, foi preparado mediante o levantamento de canteiros feitos com o rotocanteirador, com 1,08 m de largura útil e 2,40 m de comprimento, totalizando área útil de $2,59 \mathrm{~m}^{2}$. A adubação foi feita a lanço nos canteiros e incorporada no transplantio. $\mathrm{O}$ transplante das mudas nos canteiros foi feito quando as mudas atingiram cerca de $0,15 \mathrm{~m}$ de altura, aos 20 dias após a semeadura, com $0,50 \mathrm{~m}$ de espaçamento entre fileiras e de $0,25 \mathrm{~m}$ entre plantas. $\mathrm{O}$ controle de plantas infestantes foi feito com o auxílio de enxadas nas entrelinhas e manual dentro das linhas. As irrigações foram por aspersão, sempre que necessárias.

Durante o ciclo de cultivo, as alturas das plantas foram medidas quinzenalmente, entre 30 e 120 dias após o transplantio (DAT). A colheita dos capítulos florais foi feita semanalmente, desde os 20 aos 120 dias após o transplante, quando se avaliaram o número e as massas frescas. As massas secas dos capítulos florais foram obtidas após terem sido colocadas em estufa de circulação de ar forçada a $36 \pm 38^{\circ} \mathrm{C}$. No final do ciclo, quando as plantas já estavam em senescência, aos 120 DAT, foram colhidas duas plantas por parcela para a determinação das massas frescas e secas das partes aéreas.

Para estimar as superfícies de resposta às médias por tratamento, foram ajustados os modelos quadrático e base raiz quadrático. Cada componente dos modelos foi testado até o nível de 5\%, pelo teste $\mathrm{F}$, tendo sido utilizado o quadrado médio do erro experimental da matriz. Cada efeito individual do modelo escolhido foi testado até o nível de $5 \%$, pelo teste $\mathrm{F}$, corrigido em função do erro experimental, usando t calculado pelo SAEG (BANZATO \& KRONKA, 1989; RIBEIRO JÚNIOR, 2001). 


\section{RESULTADOS E DISCUSSÃO}

O padrão de crescimento em altura das plantas de calêndula foi dependente dos tratamentos, com respostas lineares e cúbicas, mas com taxas de crescimento significativamente semelhantes (Figura 1). Esses resultados indicam que as plantas podem apresentar taxas variáveis de crescimento e morfologia bem características, com modificações no final do ciclo vegetativo, em razão de fatores ambientes.

A altura média final das plantas, aos 120 dias, ficou em torno de $60,0 \mathrm{~cm}$, independente dos tratamentos. Esse valor é diferente do relatado por Sigedar et al. (1991), em que as plantas da calêndula alcançam até $45 \mathrm{~cm}$ de altura
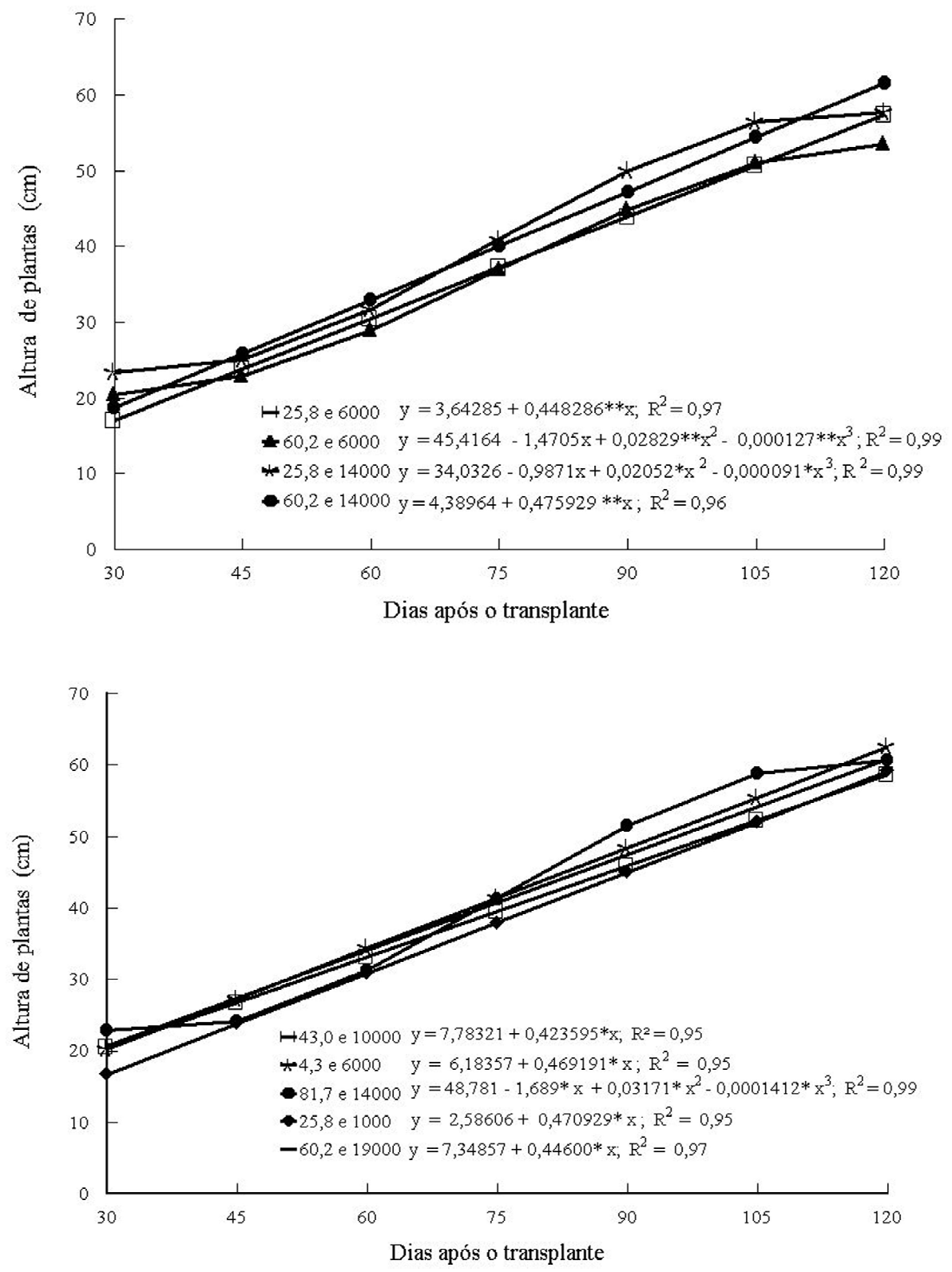

Figura 1 - Crescimento em altura das plantas de calêndula em resposta aos tratamentos com fósforo (P) e cama-de frango (C), em função de dias após o transplante. C.V. = 10,68\%. UFGD, Dourados, 2005. 
no final do ciclo. Também diferem do citado por Vieira et al. (1999) sobre a altura média final das plantas de calêndula terem variado de 29,9 a $39,9 \mathrm{~cm}$, quando cultivadas, respectivamente, com $0 \mathrm{t} \mathrm{ha}^{-1}$ de cama-de-frango $+50 \mathrm{~kg}$ $\mathrm{ha}^{-1}$ de $\mathrm{P}_{2} \mathrm{O}_{5}$ na forma de superfosfato simples e $7 \mathrm{t} \mathrm{ha}^{-1} \mathrm{de}$ cama-de-frango $+100 \mathrm{~kg} \mathrm{ha}^{-1}$ de $\mathrm{P}_{2} \mathrm{O}_{5}$. As diferenças de altura das plantas mostram que as relações fonte-dreno podem ser alteradas pelas condições de cultivo (BENINCASA, 2003; HARDER et al., 2005; LARCHER, 2000).

A produção máxima de capítulos florais da calêndula foi de $9.755,16 \mathrm{mil} \mathrm{ha}^{-1}$, obtida com o uso de $49,15 \mathrm{~kg} \mathrm{ha}^{-1} \mathrm{de}$ $\mathrm{P}_{2} \mathrm{O}_{5}$, associada a $13.401,10 \mathrm{~kg} \mathrm{ha}^{-1}$ de cama-de-frango (Figura 2). Isso indica que os sistemas vegetais são capazes de se autoregular, baseando-se na capacidade de adaptação do organismo individual e das populações (LARCHER, 2000). Segundo Kiehl (1993), o efeito benéfico da associação de adubos minerais fosfatados com orgânicos deve aumentar o $\mathrm{P}$ disponível para as plantas, além do provável efeito indireto da cama-de-frango, elevando o pH do solo e contribuindo para incremento na disponibilidade de outros nutrientes.

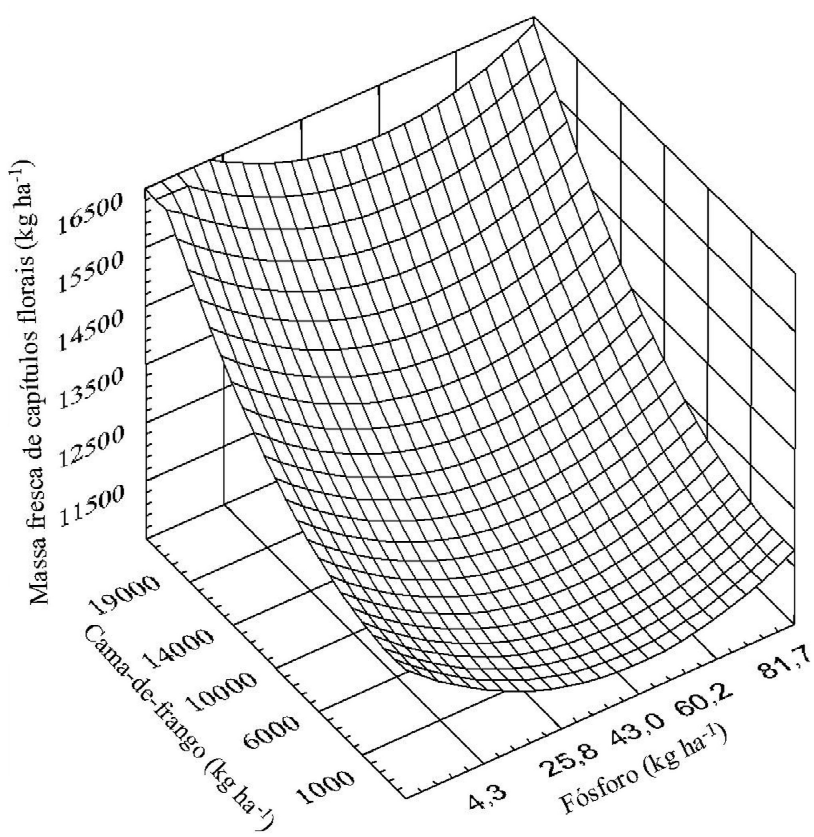

$\mathrm{y}=10384,90-30,0042 \mathrm{P}+0,0357058 * \mathrm{C}+0,305195 \mathrm{P}^{2}+$ $0,00000591905 * C^{2} R^{2}=0,91$

*significativo a $5 \%$ de probabilidade

Figura 2 - Número de capítulos florais da calêndula, em função de doses de fósforo $(\mathrm{P})$ e de cama-de-frango (C). C.V. $=14,73 \%$. UFGD, Dourados, 2005.
A maior produção $\left(11.058,89 \mathrm{~kg} \mathrm{ha}^{-1}\right)$ de massa fresca de capítulos florais de calêndula foi obtida com $49,98 \mathrm{~kg}$ ha $^{-1}$ de $\mathrm{P}_{2} \mathrm{O}_{5}$ e 13.266,59 $\mathrm{kg} \mathrm{ha}^{-1}$ de cama-de-frango (Figura 3 ). Esse resultado indica que a mistura de fertilizantes minerais fosfatados com orgânicos deve ter aumentado a disponibilidade de $\mathrm{P}$ para as plantas, provavelmente pela formação de complexo humo-fosfato e pelo revestimento dos sesquióxidos de ferro e alumínio pelo húmus, evitando a adsorção do fosfato solúvel (KIEHL, 1993). Isso porque, a matéria orgânica do solo libera parte do $\mathrm{N}$ e P, nutrientes que, via de regra, proporcionam os maiores acréscimos de produção.

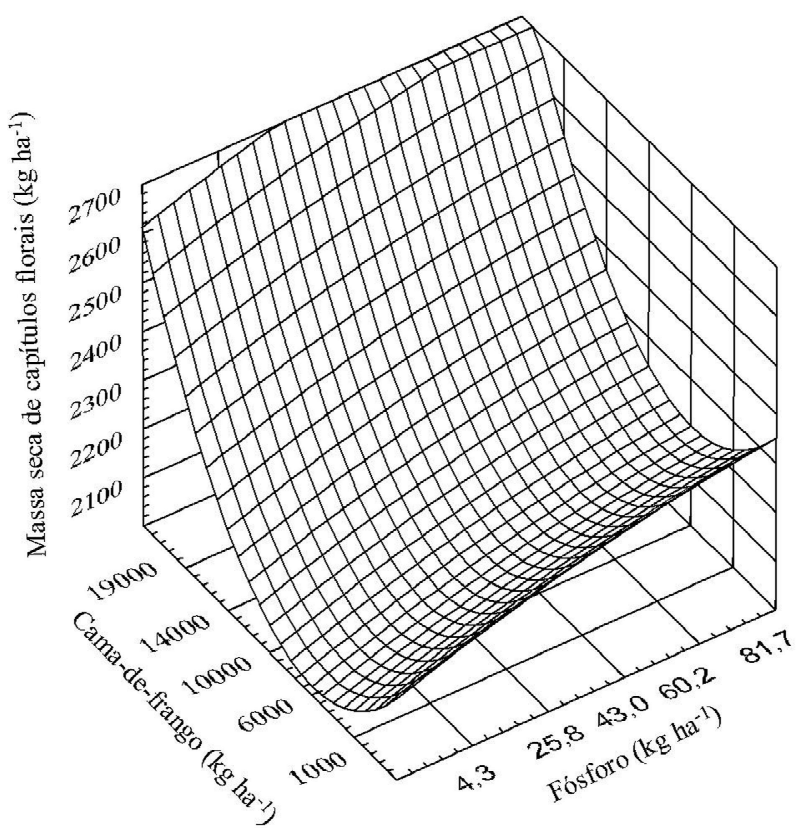

$\mathrm{y}=12196,70-46,7115 \mathrm{P}+0,01815305 * \mathrm{C}+0,467213 \mathrm{P}^{2}+$ $0,00000866182 * C^{2} R^{2}=0,92$

* significativo a $5 \%$ de probabilidade

Figura 3 - Massas frescas de capítulos florais da calêndula, em função de doses de fósforo $(\mathrm{P})$ e de cama-de-frango (C). C.V. = 15,38\%. UFGD, Dourados, 2005.

Sigedar et al. (1991), quando estudaram 0; 25 e $50 \mathrm{~kg}$ ha $^{-1}$ de $\mathrm{P}_{2} \mathrm{O}_{5}$ e $0 ; 50$ e $100 \mathrm{~kg} \mathrm{ha}^{-1}$ de $\mathrm{N}$, em experimento com calêndula, observaram que a interação entre $50 \mathrm{~kg} \mathrm{ha}^{-1} \mathrm{de}$ $\mathrm{P}_{2} \mathrm{O}_{5}$ e $100 \mathrm{~kg} \mathrm{ha}^{-1}$ de $\mathrm{N}$ aumentou o número e a massa dos capítulos florais. Vieira et al. (2002), avaliando a produção de biomassa de calêndula, em função de tipos de diásporos e cama-de-frango, observaram que as produções de massas frescas de partes aéreas $\left(343,30\right.$ a 423,73 $\mathrm{g}$ planta $\left.^{-1}\right)$, de capítulos florais $\left(37,00\right.$ a 52,54 $\mathrm{g}$ planta $\left.^{-1}\right)$, de frutos verdes 
$\left(25,62\right.$ a 34,95 g planta $\left.^{-1}\right)$ e de frutos maduros $(1,33$ a 2,22 g planta $^{-1}$ ) não foram influenciadas significativamente pelos tipos de diásporos nem pela cama-de-frango.

As produções máximas de massas secas de capítulos florais $\left(2.227,61 \mathrm{~kg} \mathrm{ha}^{-1}\right)$ foram obtidas com 39,62 $\mathrm{kg} \mathrm{ha}^{-1}$ de $\mathrm{P}_{2} \mathrm{O}_{5}$ e $8.109,75 \mathrm{~kg} \mathrm{ha}^{-1}$ de cama-de-frango (Figura 4). Esses resultados contrariam os obtidos por Vieira et al. (1999), que, estudando a influência de cama-de-frango semidecomposta e de fósforo sobre o crescimento de plantas e produção de capítulos de calêndula, verificaram que as maiores produções de massas frescas $(1.794,64 \mathrm{~kg}$ $\left.\mathrm{ha}^{-1}\right)$ e de massas secas $\left(240,96 \mathrm{~kg} \mathrm{ha}^{-1}\right)$ de capítulos de calêndula foram obtidos com o uso de $14 \mathrm{t} \mathrm{ha}^{-1}$ de camade-frango e $0 \mathrm{~g} \mathrm{ha}^{-1}$ de $\mathrm{P}_{2} \mathrm{O}_{5}$ Os capítulos de calêndula com maior massa unitária $(0,18 \mathrm{~g})$, embora em menor número (9,63 por planta), resultaram do uso de $50 \mathrm{~kg} \mathrm{ha}^{-1} \mathrm{P}_{2} \mathrm{O}_{5}$

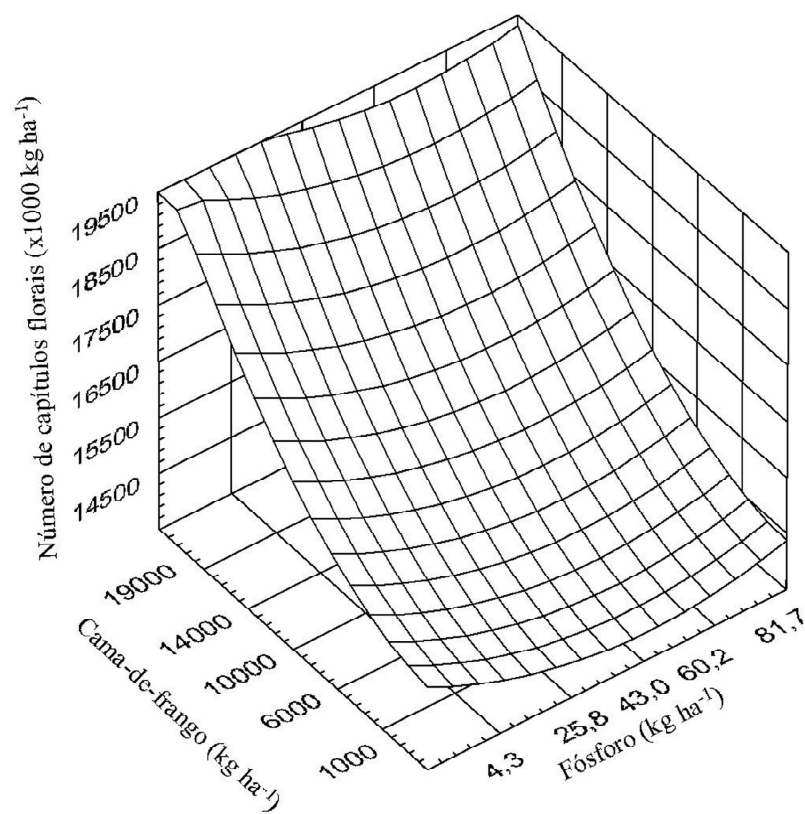

$\mathrm{y}=2127,79+2,61792 \mathrm{P}-0,0277204 * \mathrm{C}-0,00937686 \mathrm{P}^{2}-$ $0,00000231703 * \mathrm{C}^{2} ; \mathrm{R}^{2}=0,76$

*significativo a $5 \%$ de probabilidade.

Figura 4 - Massas secas dos capítulos de calêndula, em função de doses de fósforo (P) e de cama-de frango (C). C.V. $=12,38 \%$. UFGD, Dourados, 2005.

\section{CONCLUSÃO}

Nas condições em que foi desenvolvido o experimento concluiu-se que, para se obter maior produção de massa seca de capítulos florais, componente de maior importância comercial, a calêndula deve ser cultivada utilizando-se adubação com $\mathrm{H}^{\prime} 40 \mathrm{~kg} \mathrm{ha}^{-1}$ de $\mathrm{P}_{2} \mathrm{O}_{5}$ e H" 8.000 $\mathrm{kg} \mathrm{ha}^{-1}$ de cama-de-frango.

\section{AGRADECIMENTOS}

Ao CNPq, pelas bolsas concedidas e à FUNDECTMS, pelo apoio financeiro.

\section{REFERÊNCIAS BIBLIOGRÁFICAS}

BANZATTO, D. A.; KRONKA, S. do N. Experimentação agrícola. Jaboticabal: FUNEP, 1989. 247 p.

BENINCASA, M. M. P. Análise de crescimento de plantas. Jaboticabal: FUNEP, 2003. 42 p.

BERTONI, B. W.; DAMIÃO FILHO, C. F.; MORO, J. R.; PEREIRA, A. M. S.; FRANÇA, S. C. Estudo da viabilidade dos diásporos de Calendula officinalis. In: SIMPÓSIO DE PLANTAS MEDICINAIS DO BRASIL, 15., 1998, Águas de Lindóia, SP. Programas e

Resumos... Águas de Lindóia: SBPM, 1998. p. 181.

BEZÁKOVA, L.; MASTEROVÁ, I.; PAULIKOVÁ, I.; PSENAK, M. Inhibitory activity of isorhamnetin glycosides from Calendula officinalis L. on the activity of lipoxygenase. Pharmazie, v. 51, n. 2, p. 126-127, 1996.

DELLA LOGGIA, R.; TUBARO, A.; SOSA, S.; BECKER, H.; SAAR, S.; ISAAC, O. The role of triterpenoides in the topical inflamatory activity of Calendula officinalis flowers. Planta Medica, v. 60, n. 6, p. 516-520, 1994.

FONT QUER, P. Plantas medicinales: el dioscórides renovado. Espanha: Labor, 1993.

FUENTES, V.; ACOSTA, L.; DURAND, D.; RODRÍGUEZ, C.; MARTINS, G.; RAMOS, R. El cultivo de una espécie medicinal: Calendula officinalis $\mathrm{L}$. Plantas Medicinales, v. 6, p. 28-33, 1986.

HARDER, W. C.; HEREDIA ZÁRATE, N. A.; VIEIRA, M. C. Produção e renda bruta de rúcula (Eruca sativa Mill.) 'Cultivada' e de almeirão (Cichorium intybus L.)

'Amarelo', em cultivo solteiro e consorciado. Ciência e Agrotecnologia, Lavras, v. 29, n. 4, p. 775-785, 2005.

KIEHL, E. J. Fertilizantes organominerais. Piracicaba: Agronômica Ceres, 1993. 
LARCHER, W. Ecofisiologia vegetal. São Carlos: RiMa Artes e Textos, 2000. 531 p.

MARTINS, E. R.; CASTRO, D. M. de; CASTELLANI, D. C.; DIAS, J. E. Plantas medicinais. Viçosa, MG: UFV, 1994. 220 p.

MATTOS, J. K. de A. Plantas medicinais: aspectos agronômicos. Brasília, DF: [s.n.], 1996. 51 p.

MOREIRA, P. A.; MARCHETTI, M. E.; VIEIRA, M. do C.; NOVELINO, J. O.; ROBAINA, A. D.; GONÇALVES, M. C. Desenvolvimento vegetativo e teor foliar de macronutrientes da calêndula (Calendula officinalis L.) adubada com N e P. Revista Brasileira de Plantas Medicinais, Botucatu, v. 8, n. 1, p. 18-23, 2005.

RIBEIRO JÚNIOR, J. I. Análises estatísticas no SAEG. Viçosa, MG: UFV, 2001. 301 p.

SIGEDAR, P. D.; ANSERWADEKAR, K. W.; RODGE, B. $M$. Effect of different levels of nitrogen, phosphorus and potassium on growth and yield of Calendula officinalis Linn. South Indian Horticulture, New Delhi, v. 39, n. 4, p. 308-311, 1991.
TESKE, M.; TRENTINE, A. M. Compêndio de fitoterapia. Curitiba: Herbarium Laboratório Botânico, 2001. 317 p.

VENIKAR, A. D.; JANDGE, C. R. Antimicrobial activity of Calendula officinalis. Indian Journal of Indigenous Medicines, New Delhi, v. 9, n. 1/2, p. 41-44, 1993.

VIEIRA, M. C.; HEREDIA ZÁRATE, N. A.; AMORIM, P. Q. Produção de biomassa de Calendula officinalis L. em função de tipos de diásporos e cama-de-aviário. Acta Horticulture, Leuven, n. 569, p. 149-154, 2002.

VIEIRA, M. C.; HEREDIA ZÁRATE, N. A.; RAMOS, M. B. M. Crescimento e produção de capítulos de Calendula officinalis L., em função de cama-de-aviário semi-decomposta e de fósforo. Revista Brasileira de Plantas Medicinais, Botucatu, v. 1, n. 2, p. 45-51, 1999.

ZITTERL-EGLSEE, K.; SOSA, S.; JURENITSH, J.; SCHUBERT-ZSLAVECZ, M.; DELLA LOGGIA, R.; TUBARO, A.; BERTOLDI, M.; FRANZ, C. Antioedematous activities of the main triterpendiol esters of marigold (Calendula officinalis L.). Journal of Ethnopharmacology, v. 57, p. 139-144, 1997. 